\title{
The Experimental Research on Grain Storage Heat and Moisture Transfer
}

\author{
Siyu Chen ${ }^{1,2}$, Wenfu $\mathrm{Wu}^{1}$, Yan $\mathrm{Xu}^{1}$, Chunshan Liu $^{2}$, Yaqiu Zhang ${ }^{1, \text { a }}$ \\ ${ }^{1}$ College of Biological and Agricultural Engineering, Jilin University, Changchun, 130022, China; \\ ${ }^{2}$ College of Mechanical Engineering, Jiamusi University, Jiamusi, 154007, China \\ a472003220@qq.com(Corresponding Author).
}

Keywords: grain storage, temperature, relative humidity, heat and moisture transfer.

\begin{abstract}
Different moisture content corns were stored by the self-made simulated silos. Heat and moisture transfer in different initial moisture content simulated silos were analyzed during the static storage. The experiment result indicated that the bottom grain layers were acutely affected by the external condition in simulated trial silos. The average minimum temperature all appeared at the bottom of the four trial silos. Internal temperature and relative humidity at each layer increased with the increase of moisture content. In the process of the experiment, heat and moisture content mainly concentrated in the upper layer of the silo.
\end{abstract}

\section{Introduction}

Moisture and temperature are considered as two most important factors in maintaining grain quality during grain storage. Due to heat-induced natural convection currents, moisture migration occurs within the stored grain bulk [1] [2] [3].The moisture migration was mainly due to the natural convection diffusion or both. It made the air of top space and grain internal near balance [4] [5].

Internal heat sources (respiration of the biotic components of the grain mass) as well as external sources (solar radiation, seasonal variation of weather conditions) can modify the temperature of stored grain, altering the local equilibrium between the grain and its surrounding environment. Temperature gradients within the grain mass promote moisture migration from warm to cold regions and this redistribution may create spots with conditions suitable for grain deterioration [6].

Seasonal variations in ambient temperature can prompt safe moisture contents of warehousing storage grain bulks to fluctuate, due to the initial temperature gradient causing the natural convection of air in the porous medium and the migration of moisture and redistribution From the perspective of fluid natural convection in porous media, it can analyze the interactive relationship among fluid flow in the static packed bed, temperature and moisture content gradient, and would obtain the coupling mechanism of hygroscopic porous media on the flow field, temperature field and humidity field [7].

Based on these, four simulated silos were made. Corns under different water content were short-term stored in the simulated silos in order to analyze the grain heat and moisture transfer. Finally, we concluded our paper in section 4.

\section{Materials and methods}

Test materials. The corns used for test were harvested in 2014.The type of corn was JiLin Xianyu and the initial moisture content were $12.8 \%, 14.6 \%, 19.2 \%$ and $23.4 \%$ respectively.

Main instruments and equipments.Computer and acquisition system, experimental simulated silo, temperature and humidity sensor. The temperature and humidity sensors were used for testing the temperature and humidity of corns in the silo and the air humidity of top space. Sensor type was SHT10. The humidity measurement range was $0-100 \% \mathrm{RH}$ and humidity measurement precision range was $\pm 4.5 \% \mathrm{RH}$. The working voltage range was $2.4-5.5 \mathrm{~V}$.

Sensors distribution.Every simulated silo was $200 \mathrm{~mm}$ in diameter and $1000 \mathrm{~mm}$ tall. There was a $15 \mathrm{~mm}$ hole in diameter and spaced $200 \mathrm{~mm}$ apart in the longitudinal wall. Four temperature and 
humidity sensors were fixed and sealed within the longitudinal four holes respectively. The other two sensors, one for the environmental temperature and humidity measurement, another was used to measure the air temperature and humidity between silo top and grain surface. Four silos were adopted for four different moisture corns storage experiment and single simulated silo was shown in Fig.1.

Principle and methods. Weighting and labelling the corns of every silo, initial moisture content were measured using drying. The temperature and humidity sensors were fixed and sealed in the silo, different moisture content corns were poured into the silo respectively.

Experimental data were tested and automatic recording through the software and hardware system. Acquisition system collected data every 8 minutes and the experiment cycle was 6 days.

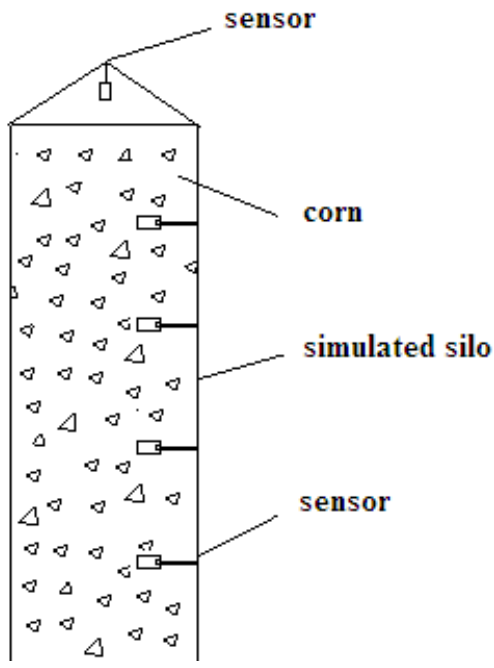

Fig.1: Sensors distribution

\section{Results and discussion}

Temperature changes in different moisture content silos.Corns initial moisture content were $12.8 \%, 14.6 \%, 19.2 \%$ and $23.4 \%$ in the simulated silos respectively. The average temperature of environment was $14^{\circ} \mathrm{C}$ and the average relative humidity was $45.06 \%$. The temperature changes of different grain layers were shown in Fig.2. It can be seen from the Fig.2 that corn at the bottom of the silo was influenced greatly by the surface temperature and the ambient temperature because the diameter and height of simulated silo was small. The average minimum temperature of four experimental silos all appeared at $200 \mathrm{~mm}$ distanced the bottom of the silo. The lowest average temperature was $3.72{ }^{\circ} \mathrm{C}$ in the $12.8 \%$ moisture content simulated silo. Other layers temperatures were about $14{ }^{\circ} \mathrm{C}$. The highest average temperature appeared at $400 \mathrm{~mm}$ distanced the bottom of the silo and the average temperature was $14.24{ }^{\circ} \mathrm{C}$.

The silo of the initial moisture content for $14.6 \%$ was fundamentally the same as $12.8 \%$. The average minimum temperature was $4.79^{\circ} \mathrm{C}$ and other layers temperatures were about $13^{\circ} \mathrm{C}$. The highest average temperature appeared at $400 \mathrm{~mm}$ distanced the bottom of the silo and the average temperature was $13.87^{\circ} \mathrm{C}$.

The lowest average temperature was $5.54^{\circ} \mathrm{C}$ in the $19.2 \%$ moisture content simulated silo. The average temperature appeared at $600 \mathrm{~mm}$ distanced the bottom of the silo and the average temperature was $16.42^{\circ} \mathrm{C}$. The highest average temperature appeared at $800 \mathrm{~mm}$ distanced the bottom of the silo and the average temperature was $18.63^{\circ} \mathrm{C}$.

The lowest average temperature was $4.91^{\circ} \mathrm{C}$ in the $23.4 \%$ moisture content simulated silo. The average temperature appeared at $600 \mathrm{~mm}$ distanced the bottom of the silo and the average temperature was $17.44^{\circ} \mathrm{C}$. The temperature and humidity sensor exceeded the measurement range at $800 \mathrm{~mm}$ distanced the bottom of the $23.4 \%$ silo. The average temperature of each layer was shown 
in Fig. 3 in different moisture content silo. The temperature of each layer increased with the increase of moisture content.

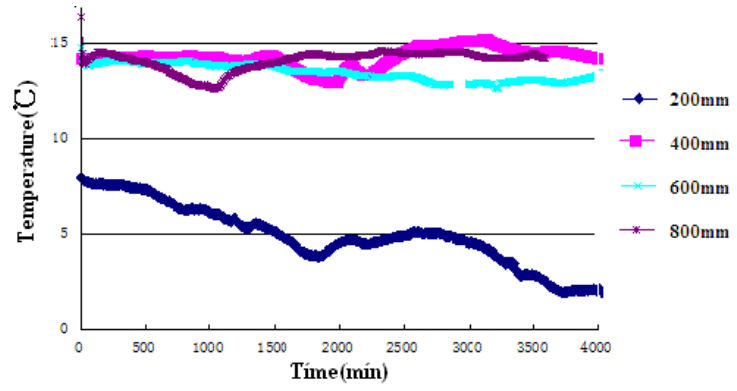

(a) $12.8 \%$

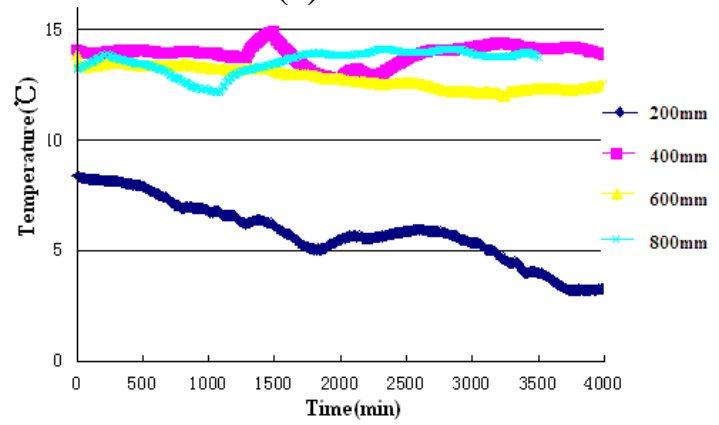

(b) $14.6 \%$

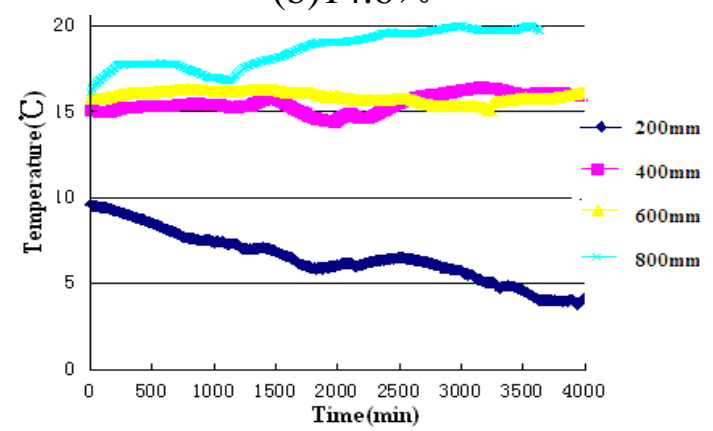

(c) $19.2 \%$

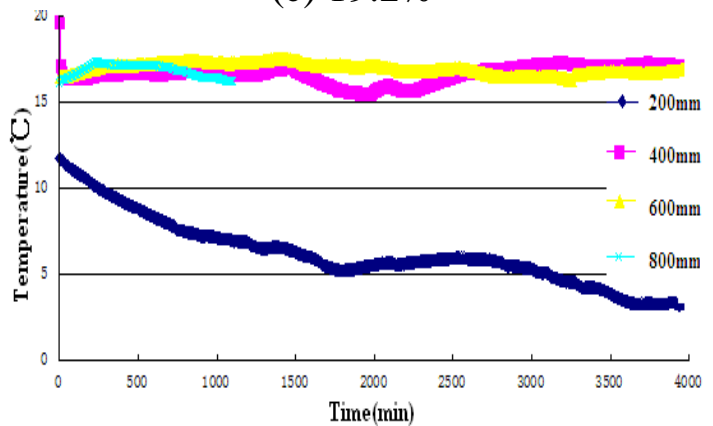

(d) $23.4 \%$

Fig.2: Temperature changes of different grain layers in different moisture content silo.

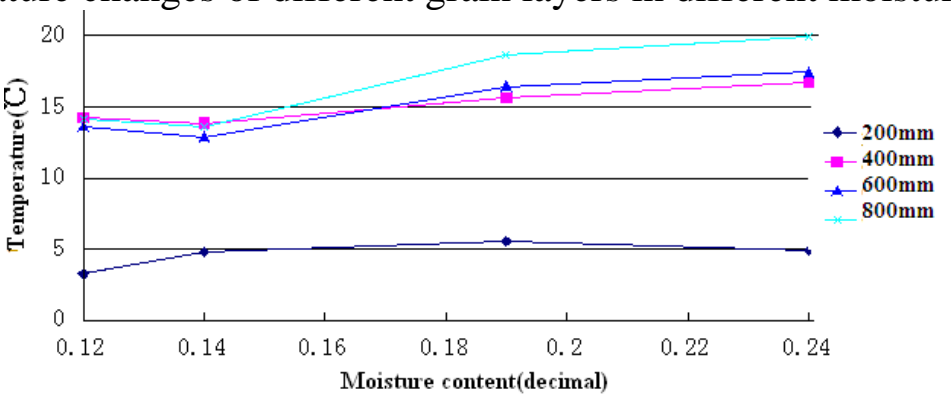

Fig.3: Average temperature of each layer 
Relative humidity changes in different moisture content silos. The humidity changes of different grain layers were shown in Fig.4. It can be observed in Fig. 4 that humidity in the silo overall increased with the increase of initial moisture content.

In the moisture of the soil by $12.8 \%$, the relative humidity was minimum at $200 \mathrm{~mm}$ distanced the bottom of the silo. The average relative humidity was $60 \%$. The highest average relative humidity appeared at $400 \mathrm{~mm}$ distanced the bottom of the silo and the average relative humidity was $68 \%$.In the moisture of the soil by $14.6 \%$, the relative humidity was minimum at $200 \mathrm{~mm}$ distanced the bottom of the silo. The average relative humidity was $64 \%$. The highest average relative humidity appeared at $400 \mathrm{~mm}$ distanced the bottom of the silo and the average relative humidity was $70 \%$.

The relative humidity was minimum at $200 \mathrm{~mm}$ distanced the bottom of the silo in the moisture content $19.2 \%$ silo. The average relative humidity was $87 \%$. Higher relative humidity appeared at $600 \mathrm{~mm}$ and $800 \mathrm{~mm}$. The average relative humidity was about $95 \%$. In the moisture content $23.4 \%$ silo, the average relative humidity was $92 \%$. The humidity sensor exceeded the measurement range at $800 \mathrm{~mm}$ distanced the bottom of the $23.4 \%$ silo. The relationship between average relative humidity and moisture content were shown in Fig. 5.

In the static storage process, the internal moisture migration is mainly due to the natural convection and diffusion of internal air. In the process of the whole test, the moisture mainly accumulated on the top of the grain in the silo when the environment temperature was lower than the grain temperature. When the environment temperature was higher than the grain temperature, the moisture mainly accumulated at the lower of the silo.

The humidity sensor exceeded the measurement range at $800 \mathrm{~mm}$ distanced the bottom of the $23.4 \%$ silo because the internal moisture had reached saturation in the experiment.

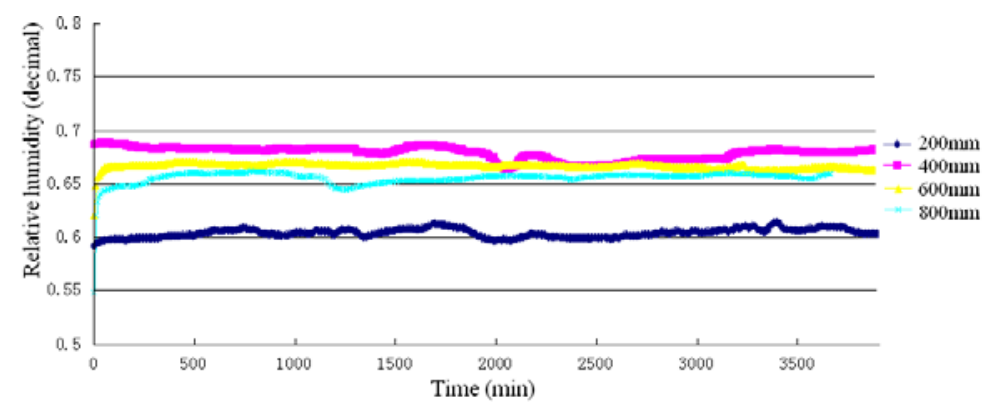

(a) $12.8 \%$

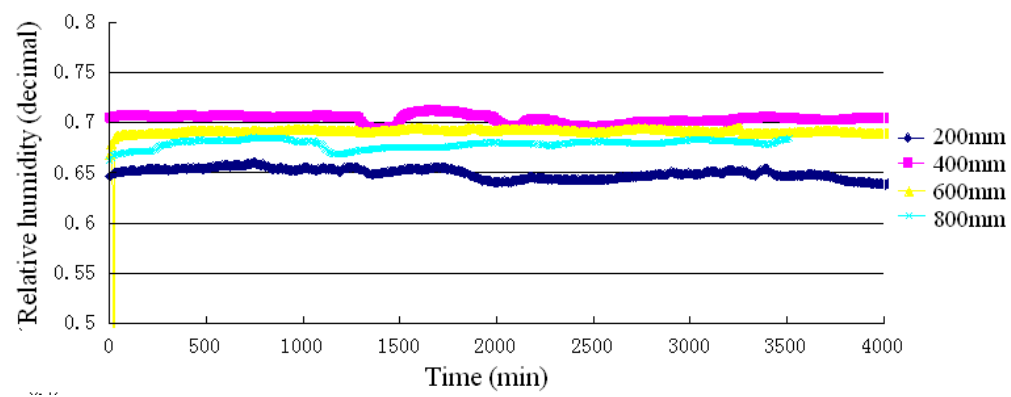

(b) $14.6 \%$

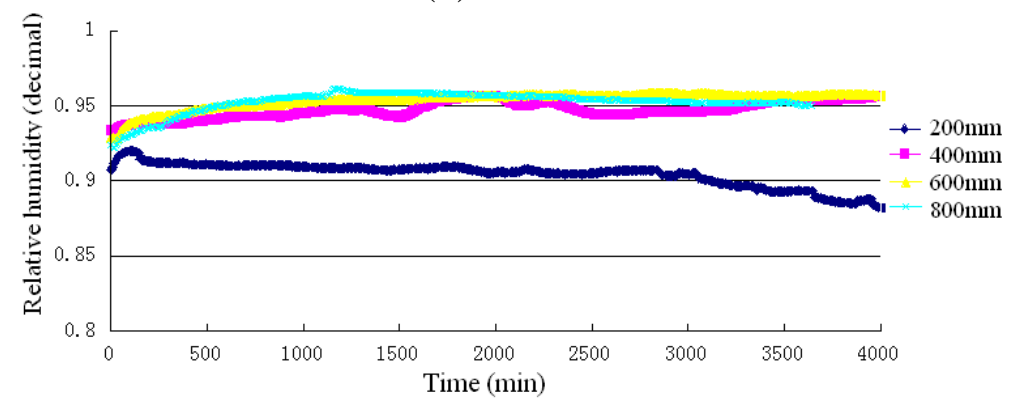

(c) $19.2 \%$ 


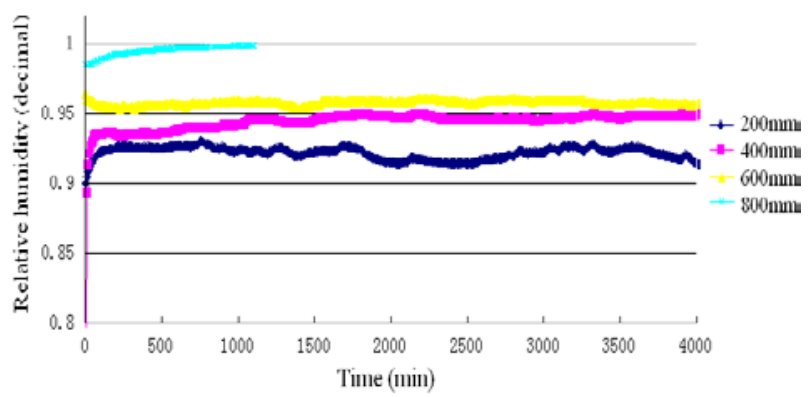

(d) $23.4 \%$

Fig.4: Relative humidity changes of different grain layers in different moisture content silo.

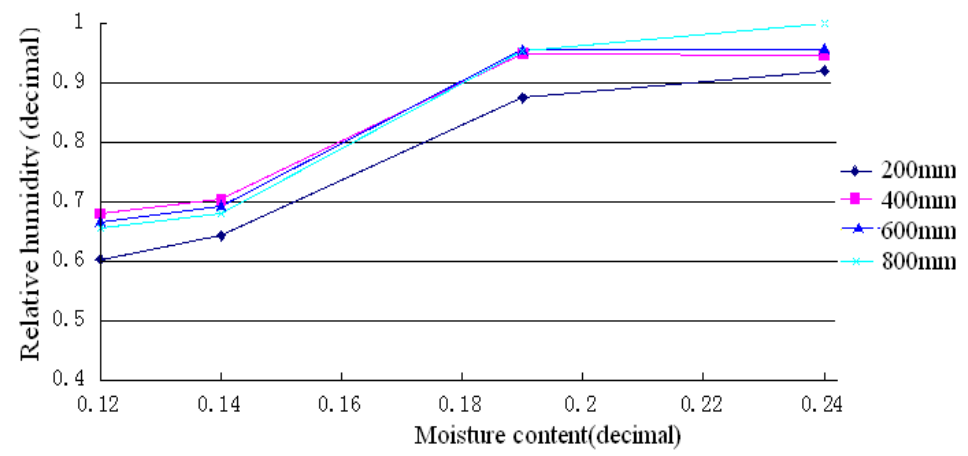

Fig.5: Relationship between relative humidity and moisture content

\section{Conclusions}

Corn at the bottom of the silo was influenced greatly by the surface temperature and the ambient temperature because the volume of simulated silo was small. The average minimum temperature of four experimental silos all appeared at $200 \mathrm{~mm}$ distanced the bottom of the silo.

Temperature and humidity inside the silo overall increased with the increase of initial moisture content. Heat and moisture mainly concentrated in upper layer of the grain.

In the static storage process, the internal moisture migration is mainly due to the natural convection and diffusion of internal air. In the process of the whole test, the moisture mainly accumulated on the top of the grain in the silo when the environment temperature was lower than the grain temperature. When the environment temperature was higher than the grain temperature, the moisture mainly accumulated at the lower of the silo.

\section{Acknowledgements}

The research work was supported by Public Welfare Industry Research Special Project of State Administration of Grain No. 201313001-07 and No. 201313001-03-04.

\section{References}

[1] Thorpe, G.R. Moisture diffusion through bulk grain subjected to a temperature gradient. Journal of Stored Products Research,18, pp.9-12, 1981.

[2] Smith, E.A. \& Sokhansanj, S. Natural convection and temperature of stored produce -a theoretical analysis. Canadian Agricultural Engineering, 32, pp.91-97, 1990.

[3] Thorpe, G.R.,Tapia, J.A.O. \& Whitaker, S. The diffusion of moisture in food grains. II. Estimation of the effective diffusivity. Journal of Stored Products Research ,27, pp.11-30, 1991.

[4] Montross, M.D., Maier, D.E. \& Haghighi, K. Validation of a finite-element stored grain ecosystem model. Transactions of the ASAE,45, pp.1465-1474, 2002. 
[5] Jayas, D.S. Mathematical modeling of heat, moisture, and gas transfer in stored grain ecosystems. In: Jayas, D.S., White, N.D.G., Muir, W.E. (Eds.), Storedgrain Ecosystems. Marcel Dekker, New York, Basel, Hong Kong, pp. 527-567, 1995.

[6] Khankari K.K., Morey R.V. \& Patankar S.V. Mathematical model for moisture diffusion in stored grain due to temperature gradients. Transactions of the ASAE, 37(5), pp.1591-1604, 1994.

[7] Zhongquan B. Research of coupled heat and moisture transfer in hygroscopic. Master thesis: Shandong Jianzhu University, 2013. 